\title{
LÚCIO FLÁVIO - SOBRE A CENSURA AO LIVRO E À ADAPTAÇÃO CINEMATOGRÁFICA
}

\begin{abstract}
Sandra Reimao ${ }^{1}$
Resumo: O livro Lúcio Flávio passageiro da agonia, escrito por José Louzeiro, e publicado pela Editora Civilização Brasileira em 1975, gerou quatro pareceres discordantes, tendo sido finalmente liberado. Em um segundo momento, a possibilidade da adaptação do livro para filme foi tema de parecer prévio do Departamento de Censura de Diversões Públicas, DCDP, que indicou cortes e modificações. E, por fim, em um terceiro momento, o filme foi examinado, foi vetado e, depois de cortes e modificações, liberado para maiores de 18 anos. Esse artigo reconstrói e analisa os passos principais da tumultuada trajetória desse livro e também de sua adaptação cinematográfica pelo DCDP. O filme Lúcio Flávio - passageiro da agonia, dirigido por Hector Babenco, com roteiro de José Louzeiro, Hector Babenco e Jorge Duran, protagonizado por Reginaldo Faria, lançado em 1977, foi visto por mais de cinco milhões de pessoas e foi uma forte denúncia da polícia violenta e corrupta.

Palavras-chave: Lúcio Flávio - passageiro da agonia, José Louzeiro, censura, DCDP
\end{abstract}

\section{LUCIO FLAVIO - REGARDING THE CENSORSHIP OF THE NOVEL AND ITS}

CINEMATOGRAPHIC ADAPTATION

\begin{abstract}
Written by José Louzeiro and published by the EB in 1975, Lúcio Flávio passanger of agony generated four dissonant censorship mementos- eventually its publishing was permitted. Following this event, the movie adaptation of the same book underwent previous censorship by the DCDP (Department of Public Entertainment Censorship), an official organ that demanded cuts and modifications. Finally, the movie per se was vetoed, adapted and at the end allowed to audiences over 18 . This article aims at retracing the stages of this conflict-loaded book, as well as its movie adaptation. The motion picture, under the same name, directed by Hector Babenco and Jorge Duran, had over 5 million viewers in 1977, and constituted a strident denunciation of police corruption and violence.
\end{abstract}

Key words: Lúcio Flávio passanger of agony, censorship, DCDP

${ }^{1}$ Professora na Universidade de São Paulo (USP) e Bolsista de Produtividade CNPq (1D). E-mail: sandra.reimao@gmail.com 


\section{LÚCIO FLÁVIO - SOBRE A CENSURA AO LIVRO E À ADAPTAÇÃO}

\section{CINEMATOGRÁFICA}

\section{INTRODUÇÃO}

Há uma caixa nos arquivos do Departamento de Censura de Diversões Públicas, DCDP, uma pasta indicada como O caso Lou - assim é se lhe parece e Lúcio Flávio - passageiro da agonia. Os livros de Carlos Heitor Cony e José Louzeiro foram publicados Editora Civilização Brasileira em 1975 como os volumes iniciais de uma coleção denominada Romance-reportagem.

Não há indicações de como esses livros foram encaminhados ao DCDP. Em lá estando, seguiram-se o tramite usual: encaminhamento a censores-pareceristas. Os pareceres teriam, por finalidade, subsidiar a decisão de interação ou liberação das obras. (cf. Reimão, 2011: 17-56)

O livro de Carlos Heitor Cony foi liberado no primeiro parecer. Já com a obra de José Louzeiro a história foi mais tumultuada e complexa.

Vejamos os capítulos dessa história mais de perto:

\section{LÚCIO FLÁVIO - UM LIVRO, QUATRO PARECERES}

O livro gerou quatro pareceres discordantes (dois pela interdição, um inconclusivo e um pela liberação) tendo sido finalmente liberado.

O primeiro parecer (812/76), de 12 de maio, assinado pelo técnico de censura Augusto da Costa indica a interdição e o faz por três motivos:

1) mensagem negativa pois "apresenta o bandido com uma aureola de bom moço e a polícia como única culpada por ele ter enveredado no crime"; 2) "desmoraliza o aparelho policial apresentando alguns de seus integrantes como corruptos /e/ (...) como tarados"; 3) "O palavreado é do mais baixo calão, pornográfico". (Sobre os censores, ver Stephanou, 2001)

O segundo parecer (861/76), de 20 de maio, assinado por Maria Ribeiro de Almeida, tem uma visão totalmente diferente do primeiro no que tange ao personagem título que, segundo a parecerista-censora, é retratado no livro como "um homem audacioso e inteligente, que forçado pelas circunstâncias se transformou em herói (ou bandido) (...) perseguido pelas autoridades". Na mesma linha de argumentação, o parecer destaca que o personagemtítulo foi "covardemente assassinado, por um companheiro de cela". 


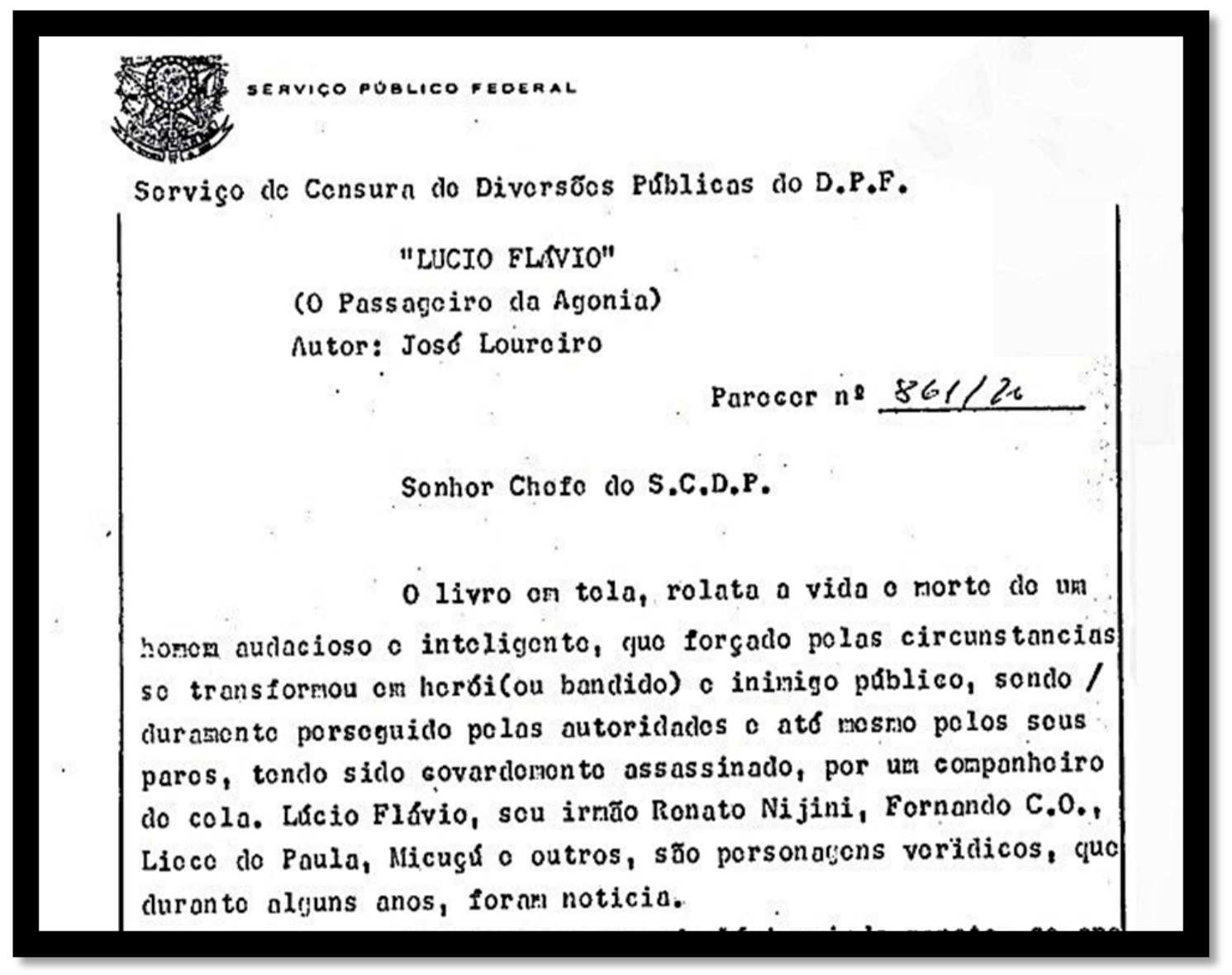

A censora, depois de observar que tanto o personagem-título quanto várias outras presentes no romance são "personagens verídicos que, durante alguns anos foram notícia", salienta que antes de morrer Lúcio Flávio "expiou seus erros e pecados".

O parecer ainda indica que "o linguajar é do mais baixo calão até hoje usado" e que o livro é contra "elementos que representam o lado deteriorado da polícia". Ou seja, o parecer não afirma que o romance visa denegrir a imagem da polícia e sim que coloca-se contra os polícias corruptos.

Surpreendentemente, de maneira incoerente com a ressalva feita de que apenas alguns elementos da polícia são deteriorados, o parecer indica o veto, pois "as acusações são feitas com tal habilidade e astúcia que se chega a duvidar que seja fruto apenas da imaginação fértil do autor." E conclui: "Os fatos são evidentes e mostram os métodos monstruosos praticados nas delegacias e presídios".

O terceiro parecer (324/76), inclonclusivo, assinado por Hellé Prudente Carvalhedo em 24/06/1976, começa afirmando que a linguagem de baixo calão é "própria do ambiente em que se desenrolam os fatos"; que a crítica à organização policial é genérica e, por fim, a trajetória de Lúcio Flávio "embora narrada de forma a humanizar e desculpar seus erros, revela-se condenatória (...). Não há a preocupação de criar um mito".

Depois dessas ponderações, o parecer afirma que o veto ao livro, caso venha a ocorrer, seria devido às "acusações acerca de corrupção de policiais (...) citações constantes de pessoas reais" e que esse tipo de problema foge "à atribuição censória no que diz respeito às publicações literárias". 
O parecer 325/76 de J. Antonio S. Pedroso, de 24/06/1976 começa por localizar que o personagem-protagonista é "o conhecido assaltante Lúcio Flávio Vilar Lírio, famoso por suas fugas espetaculares e prisões rumorosas, amplamente divulgadas pela imprensa".

A seguir, o parecer afirma que a obra apresenta-se como um romance-reportagem e que "o livro procura sempre emprestar aos fatos o máximo de realidade" e que a presença de palavras e termos chulos nos diálogos são "desculpáveis pela características do veículo, livro, e pela fidelidade (...) na representação dos personagens” (grifo nosso).

O parecer indica a liberação do livro pelo motivo já apontado no parecer 3, qual seja, que a narrativa não induz ao crime "pois relata mais percalços e desgraças do personagem central que seus efeitos vitoriosos". No final, em uma redação um tanto confusa, é destacado que a tortura a presos, presente na obra, pode desestimular o crime.

Não sabemos dizer se os censores-pareceristas conheciam os outros pareceres. Aparentemente os dois pareceres iniciais foram elaborados de forma independente. Deduz-se que os pareceres 1 e 2 não tiveram continuidade, ou seja, não foram utilizados como subsídios para despachos de interdição. Quanto aos pareceres 3 e 4, a coincidência de datas indica que eles devem ter sido simultaneamente solicitados.

\section{SOBRE A ADAPTAÇÃO DO LIVRO PARA O CINEMA:}

\section{A PERGUNTA DE ROBERTO FARIAS}

Em 2 de agosto de 1976, Roberto Farias, diretor geral da Empresa Brasileira de Filmes S.A., Embrafilme, escreveu para Rogério Nunes, diretor do DCDP, indagando sobre a viabilidade da adaptação para cinema do livro, do ponto de vista daquela órgão censório.

"Encontrando-se em tramitação nesta Empresa um projeto de filme cujo roteiro baseia-se no livro Lúcio Flávio - passageiro da agonia (...) agradeceria se nos fosse dado conhecer, por antecipação, o ponto-de-vista da censura sobre a conveniência de participarmos desse empreendimento.

Lembro que não pesa sobre o livro nenhuma restrição de parte do órgão dirigido por V.Sa.(...)" 


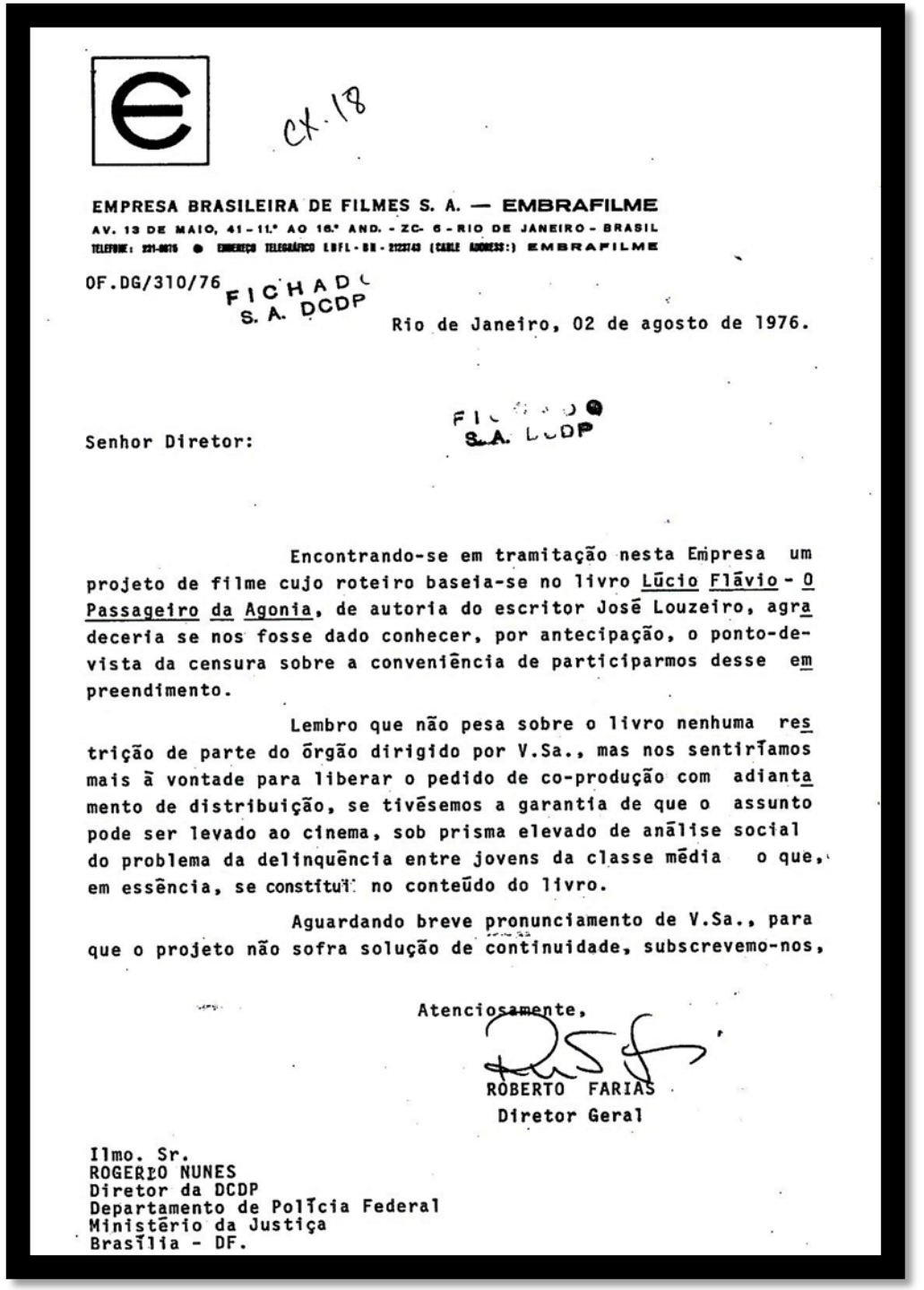

Na realidade, antes mesmo do pedido formal de Roberto Farias já havia sido elabom rado no DCDP um parecer a respeito dessa adaptação - com data de 24 de junho de 1976, assinado por Hellé Prudente Carvalhedo e J. Antonio S. Pedroso - os mesmos autores dos pareceres 3 e 4 .

A manifestação dos censores em respeito já estava feita em data anterior à questão de Roberto Farias, o parecer sobre a "Transformação do livro em roteiro para filme cinematográfico” (326/76) começa considerando que o filme terá apelo comercial devido à violência e por ser um caso real. A seguir, o parecer fala da grande capacidade de comunicação do cinema, especialmente para criar mitos e acaba por concluir que:

“(...) consideramos viável a transformação do livro em roteiro cinematográfico, desde que sejam configurados, de forma clara, o arrependimento do criminoso com seu estilo de vida (...) e, finalmente, seu propósito em tentar regenerar-se, dias antes de ser morto por seu companheiro de cela".

O parecer salienta ainda que o filme deva mostrar policiais "em serviço normal". 
Ao parecer 326/76 seguiram-se ainda:

1) Ofício (508/76) de Moacyr Coelho, diretor geral do DCDP ao Ministro da Justiça, Armando Falcão, relatando o caso e afirmando que há 25 palavras de baixo calão no livro mas que "a proibição do livro (...) somente viria a aumentar a curiosidade popular em torno do criminoso"

2) Manifestação do chefe de gabinete, Alberto Rocha, ao Ministro afirmando que o livro "não incensa um criminoso" e que é importante que "a sociedade conheça seus reais problemas".

3) Correspondência de Fernando Falcão, assessor especial, de agosto de 1976 (sem indicação de dia) ao Ministro condensando as posturas de Moacyr Coelho pela liberação do livro.

4) Ofício (584/76) do Diretor do DCDP ao diretor-geral da Embrafilme informando que o caso foi apresentado ao Ministro;

5) Novo ofício (663/76) do Diretor do DCDP ao diretor-geral da Embrafilme informando "não haver inconveniente, sob o ponto de vista censório, no aproveitamento do roteiro de filme inspirado no livro Lúcio Flávio - passageiro da agonia, de José Louzeiro".

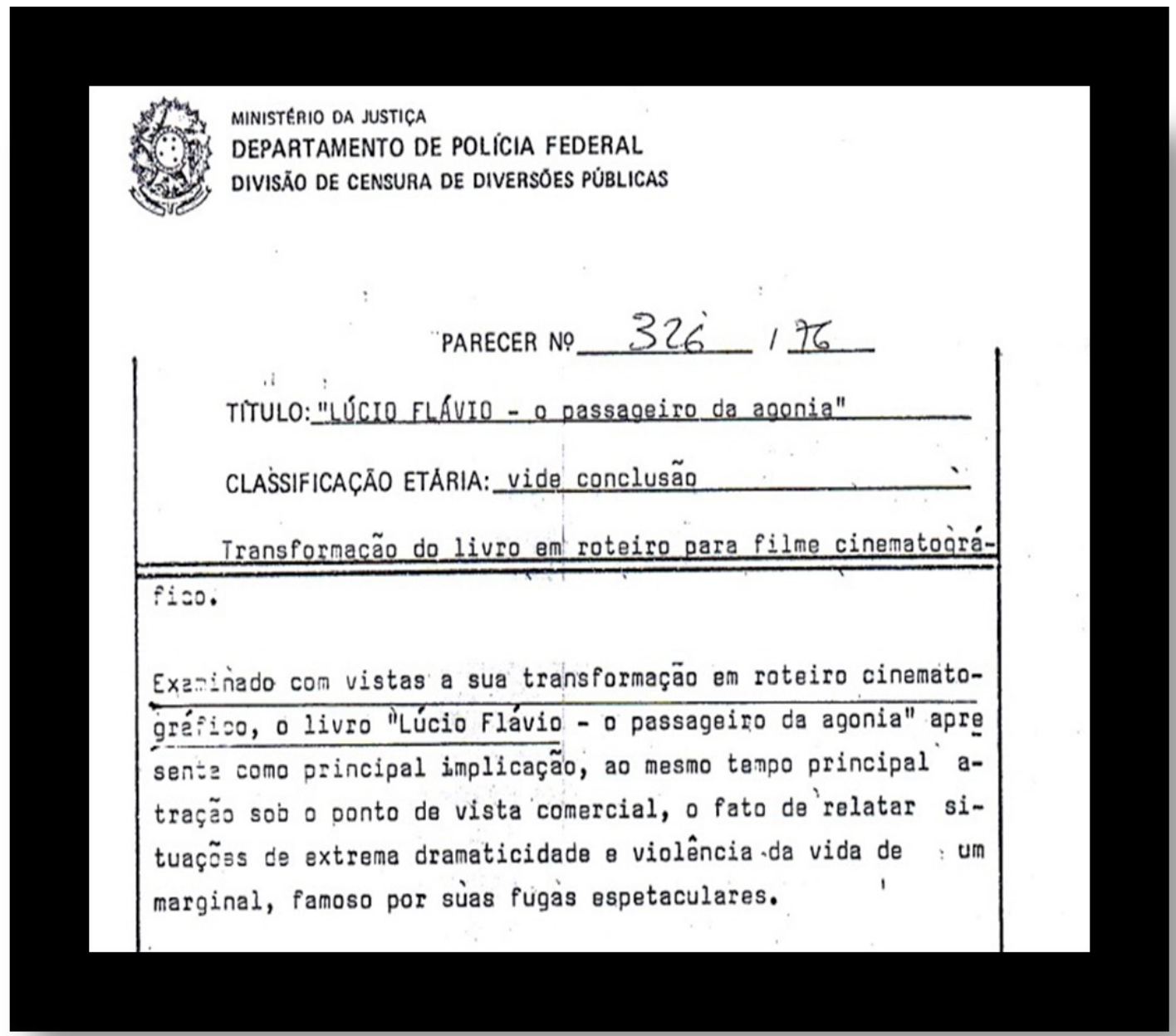


Encerrando, o ofício assinala que o filme deve cuidar-se para "não apresentar cenas ou situações que possam provocar incitamento contra as autoridades e seus agentes, proibidas pela legislação em vigor" e toma o cuidado que indicar o Decreto 20493, artigo 41, alínea d como fonte para essa ressalva.

O Decreto 20493, de 24 de janeiro de 1946, criou e regulamentou Serviço de Censura e Diversões Públicas. Citemos o Artigo 41:

Art. 41. Será negada a autorização sempre que a representação, exibição ou transmissão radiotelefônica:

a) contiver qualquer ofensa ao decoro público;

b) contiver cenas de ferocidade ou for capaz de sugerir a prática de crimes;

c) divulgar ou induzir aos maus costumes;

d) for capaz de provocar incitamento contra o regime vigente, a ordem pública, as autoridades constituídas e seus agentes.

e) Puder prejudicar a cordialidade das relações com outros povos;

f) for ofensivo às coletividades ou às religiões;

g) ferir, por qualquer forma, a dignidade ou o interesse nacionais;

h) induzir ao desprestígio das forças armadas.

\section{POLÍCIA, BANDIDO, JORNAIS, LIVROS E CINEMA - A VISÃO DO DCDP}

O conjunto dos documentos censórios relativos ao livro Lúcio Flávio - passageiro da agonia nos dá ocasião para dois âmbitos de reflexão: o primeiro deles é sobre os argumentos utilizados pelos censores pra justificar a interdição de uma obra: a suposta louvação do crime, da contravenção, em contraposição à ordem é o primeiro deles; e a possibilidade de denegrir, de manchar a reputação da polícia é outro.

As observações sobre se o livro é ou não uma louvação e uma indução ao crime são centrais nos quatro pareceres, sendo que só o primeiro conclui que sim. A questão da corrupção policial é decisiva para os vetos dos pareceres 1 e 2 , já o parecer 3 faz a ressalva que se essa denúncia disser respeito a pessoas concretas a questão extrapolaria as funções do DCDP.

Uma segunda ordem de questões que esses pareceres censórios permitem a abordagem é a da especificidade dos diversos meios de comunicação - do ponto de vista do DCDP.

Comentemos inicialmente a relação entre livros e jornais tal como assinaladas nos pareceres censórios.

Os pareceres 2 e 4 indicam que os fatos da vida do personagem-título do livro Lúcio Flávio Vilar Lírio já foram amplamente noticiados pelos jornais. Sendo que o parecer 4 indica o gênero de livro um romance-reportagem e que "o livro procura sempre emprestar aos fatos o máximo de realidade" e que a presença de palavras e termos chulos nos diálogos são "desculpáveis pela características do veículo, livro, e pela fidelidade (...) na representação dos personagens" (grifo nosso). O parecer não explicita, mas podemos concluir que o que ele está afirmando é que a leitura de livros pressupõe um receptor com uma postura mais adulta e informada. 
Essa consciência de que os livros atingem um público menor que os jornais fica clara na correspondência de Alberto Rocha para o Ministro da Justiça. Depois de falar do livro $O$ caso Lou o missivista afirma: "Tudo que se diz no livro já foi, ad nauseam, publicado pelos jornais, com público muito maior e mais indiscriminado" (grifo nosso).

Essa correspondência do chefe de gabinete diverge totalmente dos pareceres 1 a 4 em relação à representação da polícia no livro em questão. Ao contrário dos pareceres, essa carta apóia que o livro denuncie os métodos e as conexões da polícia com o mundo do crime, pois elas "existem e suprimi-las em uma obra de ficção não chega a significar a limpeza que a realidade exige e que tantas autoridades se tem dedicado com resultados muito relativos" (grifo nosso). Mais do que isso, o chefe de gabinete afirma que é preciso conscientizar a sociedade para que essa faça pressão para corrigir a polícia e cita, nesse sentido, o filme Sérpico, sobre a polícia de Nova York. Esse filme, dirigido por Sidney Lumet com Al Pacino no papel-título, conta a história de um policial honesto no meio de um grupo corrupto.

Os jornais são vistos pelos documentos censórios acima citados como dirigidos a um público mais amplo, menos especificado, e, portanto, deduz-se, com menor capacidade de julgamento que os livros. Já o cinema, além de abranger um público mais genérico é também visto como tendo uma linguagem e uma forma de recepção mais emotiva. O parecer sobre a "Transformação do livro em roteiro para filme cinematográfico" (326/76) é claro nesse sentido:

"Com maior poder de comunicação em termos de massa, o cinema, por suas características, deverá procurar as situações de maior impacto visual, justamente aspectos de assaltos, detalhes de fugas, brigas entre os prisioneiros, torturas e outros aspectos que no livro são diluídos na introspecção e recriminação de Lúcio Flávio de seus próprios atos". (grifo nosso)

Ou seja, a forma narrativa cinematográfica tende a privilegiar a ação e com isso não apresentar a reflexão interna, auto recriminadora, do personagem Lúcio Flavio sobre seus atos.

Além disso, segundo o parecer, o filme, por esse privilégio da ação, pode induzir a criação de mitos:

"A exploração exagerada da figura do criminoso frio, do prisioneiro que não hesita em fazer valer sua autoridade dentro da cela (...) transformará Lúcio Flávio no herói que o livro não pretendeu".

Para evitar essa heroização do protagonista e do crime o parecer sobre a adaptação cinematográfica, além de afirmar que os policiais devem ser mostrados em seus "serviços normais", chega a especificar alterações a serem feitas, indicando que:

1) deve-se reduzir cenas onde aparecem "planejamento de assalto, revolta na penitenciária";

2) na revolta na penitenciária "os presidiários deverão necessariamente atirar primeiro, gerando a repressão"; 
3) a cena de tortura "deve ser simplificada e, se possível, descaracterizar a ação como passada numa delegacia policial". Sobre a cena de tortura o grau de intervenção do parecer é tão elevado que ele se permite sugerir que essa "seqüência poderia ter se passado" na solitária de um subúrbio distante e não “'numa delegacia do centro” como marca o livro”.

Além de sugerir modificações o parecer julga o potencial de adaptação do livro que "oferece possibilidades ilimitadas para um bom roteiro", para depois insistir que a adaptação deve se manter nos trilhos, qual seja, "mantenha o espírito do livro: narrar o fato e não transformar criminosos em mártires do sistema ou da sociedade".

Mais tarde, decorridos 14 meses, em 9 de outubro de 1977, no exame do filme realizado, o primeiro parecer (4398/77) inicia-se exatamente com considerações sobre a especificidade do cinema. Citando:

\footnotetext{
"tendo em vista as seguintes considerações: -cena e áudio atingem muito mais a sensibilidade do que a palavra escrita; -a força da penetração do veiculo cinema, no circuito comercial, é comparativamente mais poderoso do que o da obra literária;
}

Depois dessas considerações sobre o meio, o parecer sobre o filme enfoca questões da história propriamente dita, destacando que: o filme fala do tempo presente; o protagonista é apresentado como vítima; e o filme não mostra sanção aos policiais corruptos. Essas considerações levam o parecer a indicar a não liberação do filme.

Menos de 10 dias depois desse parecer, em 18 de outubro, a empresa H. B. Filmes informa ao DCDP que ao final do último rolo acrescentou a seguinte informação:

\section{“OS POLICIAIS QUE PARTICIPARAM DESSA OCORRENCIA JÁ NÃO PERTENCEM}

\section{AOS QUADROS POLICIAIS E JÁ SOFRERAM AS SANÇOES PENAIS ADEQUADAS”}

e que com isso acredita que "salvaguarda a figura respeitável do policial, bem como a nobreza de sua missão em defesa da sociedade.

No mesmo dia em que recebeu essa correspondência o DCDP emite parecer (4430/77) liberando o filme para 18 anos desde que obedecidos 4 cortes indicados nesse parecer.

Em Roteiro da intolerância - a censura cinematográfica no Brasil, do pesquisador Inimá Simões, pioneiro no estudo dos arquivos cinematográficos do DCDP, o autor vincula a liberação do filme à demissão do general Sylvio Frota, ministro do Exército, conhecido como um radical que não desejava a redemocratização do país, conhecido como um militar "linha dura" que se opunha ao projeto de abertura política de Geisel :

"O filme foi liberado uma semana depois do afastamento do general Silvio Frota num episódio que representou o momento decisivo a favor da abertura política depois de inúmeras batalhas internas desde o início do governo Geisel, com pesadas baixas." (Simões, 1998: 201) 
Elio Gaspari em A ditadura encurralada, ao analisar a demissão do ministro Sylvio Frota afirma que era uma questão de enfrentamento entre "a anarquia militar e o poder republicano do presidente", enfrentamento esse "que o regime evitava desde 1964" e que ao efetuar a demissão "coube ao general Ernesto Geisel a defesa do poder constitucional” (Gaspari, 2004: 14). Após a morte de Sylvio Frota, em 1996, foi publicado, com o título Ideais traídos, um texto autobiográfico em que o ex-ministro explicava a sua versão dos fatos.

O conjunto dos quatro pareceres relativos ao livro Lúcio Flávio - passageiro da agonia, acrescido daquele que enfoca a possibilidade da adaptação e mais dois sobre o filme e mais as correspondências com o Ministro sobre o tema mostram agentes censórios conscientes de suas funções de manutenção da ordem vigente, tal qual a polícia, e argumentando em como executá-la. Esta argumentação inclui reflexões sobre os diferentes meios de comunicação. Nesse caso, a atuação dos censores e assessores é muito distinta daquele estereótipo folclórico que vê a censura como destrambelhada e ignorante. Em alguns casos, ela o foi, mas não em todos. Embora sempre nefasta.

Os censores e assessores do caso em foco parecem ter consciência de que a função de censura a livros "não é apenas motivada pela interdição, articulando-se em cada época, com a questão da manutenção ou subversão das hierarquias (...)"(Belo, 2002: 56), como observou André Belo em História \& livro e leitura.

\section{ANOTAÇÃO FINAL}

O parecerista que redigiu o texto sobre a "transformação do livro em roteiro para filme cinematográfico" afirmou que o filme tinha uma implicação que era "ao mesmo tempo principal atração sob o ponto de vista comercial" que era o fato de retratar uma época e personagens reais e de se concentrar em "relatar situações de extrema dramaticidade e violência da vida de um marginal, famoso por suas fugas espetaculares".

A observação do parecerista revelou-se um prognóstico verdadeiro: o país estava sedento de ver-se nas telas e o filme Lúcio Flávio - passageiro da agonia, dirigido por Hector Babenco, com roteiro de José Louzeiro, Hector Babenco e Jorge Duran, protagonizado por Reginaldo Faria foi "um dos maiores êxitos do cinema brasileiro contemporâneo, tendo sido visto por mais de cinco milhões de pessoas", informa o Dicionário de Filmes Brasileiros, de Antônio Leão da Silva Neto.

A revista Veja na edição de 8 de março de 1978 dedicou a capa e uma matéria de cinco páginas ao filme Lúcio Flávio - passageiro da agonia, com o título 'A realidade em cena' e o subtítulo 'Cem cinemas mostram "Lúcio Flávio e o "esquadrão da morte"” onde o certo e o torto se confundem”. A matéria afirma que "a história de 'Lúcio Flávio' é a da violência policial brasileira" e que o filme parece "ter descoberto o dom de falar às platéias sobre elas mesmas".

Graças, especialmente, a um escritor audacioso e a um cineasta ousado, José Louzeiro e Hector Babenco, a polícia corrupta e violenta com a qual os espectadores conviviam estava sendo naquele momento, enfim, desmascarada. Um passo na história do cinema nacional; um passo na história do Brasil, sob ditadura militar, tentando caminhar em direção à construção de uma sociedade democrática. 
BIBLIOGRAFIA:

Belo, André. História \& Livro e leitura. Belo Horizonte: Autêntica, 2002.

Frota, Sylvio. Ideais traídos. Rio de Janeiro: Jorge Zahar Ed., 2006.

Gaspari, Elio. A ditadura encurralada. São Paulo: Companhia das Letras, 2004.

Reimão, Sandra. Repressão e resistência: censura a livros na ditadura militar. São Paulo: Edusp/ FAPESP, 2011

Silva Neto, Antonio Leão. Dicionário de Filmes Brasileiros. São Paulo: Edição Autor, 2006

Simões, Inimá. Roteiro da Intolerância. São Paulo: Ed. Senac/ Ed. Terceiro Nome, 1998

Stephanou, Alexandre Ayub. Censura no regime militar e militarização das artes. Porto Alegre, EDIPUCRS, 2001.

Revista Veja - edição de 8 de março de 1978. 